\title{
MANAJEMEN KESAN MELALUI FOTO SELFIE DALAM FACEBOOK: STUDI FENOMENOLOGI PADA MAHASISWA ILMU KOMUNIKASI UMS
}

\author{
Puspa Aqirul Mala \\ Program Studi Ilmu Komunikasi \\ Universitas Muhammadiyah Surakarta \\ Email: puspa.aqirulmala@gmail.com
}

\begin{abstract}
This research explores about selfies phenomenon, especially how people managing their self-presentation through selfies on the Facebook. Computer Mediated Communications (CMC) and Erving Goffman's Dramaturgi become basic theory in this research. Six informants were active uploaded their selfies and all of them are students of Communications Science in Muhammadiyah University of Surakarta. Phenomenology qualitative data result that informants are active managing their visual impression management on Facebook. They consider that Facebook is a stage and themself is an actor, so they can managing their selfies easily. Formed the charactheristic of CMC consist of: interactive, editable, de massified, and asynchronity.
\end{abstract}

Keywords: selfies, self-presentation, impression management, phenomenology, CMC

\section{A. PENDAHULUAN}

Keberadaan teknologi dari masa ke masa menimbulkan ciri khusus yang digunakan manusia dalam berkomunikasi. Teknologi memunculkan cara lain manusia dalam berkomunikasi. Cara tersebut dijembatani oleh media komputer yang lebih lanjut disebut (Computer Mediated Communications) atau CMC. CMC adalah istilah yang digunakan untuk melakukan komunikasi antara dua orang atau lebih dengan menggunakan komputer sebagai media dan jaringan internet untuk menyambungkan pesannya. Dengan adanya CMC, manusia dalam berkomunikasi mulai meninggalkan cara berkomunikasi secara konvensional. Sehingga tidak harus bertatap muka secara langsung. CMC memiliki ciriyang membedakan dengan cara berkomunikasi secara konvensional antara lain: interaktivitas yang terjadi semakin sering dilakukan, sifat de massified atau pengiriman pesan dari individu ke khalayak dalam jumlah banyak, dan asyncronity atau pesan yang terkirim tidak terikat oleh waktu sehingga penerima pesan mudah mengabaikan pesan.
Salah satu contoh CMC adalah berkomunikasi melalui Facebook. Penggunaan Facebook sebagai situs jejaring sosial semakin banyak peminatnya. Catatan dari alexa.com mengungkapkan Facebook tetap menjadi situs yang paling banyak dikunjungi di Indonesia, (Julianita, 2012:3). Komunikasi di Facebook memunculkan berbagai fenomena sosial, salah satunya selfie. Selfie adalah cara menampilkan diri dengan memfoto diri tanpa bantuan orang lain. Selfie kemudian menjadi alternatif manusia dalam mempresentasikan dirinya dalam bentuk visual.

Erving Goffman dalam Ruben (2013) mengungkapkan ekspresi diri dapat dimetaforakan ketika setiap individu memainkan peran di atas panggung yang dibuatnya atau melakukan dramaturgi. Kenetth Burke dalam Ruben (2013) juga mengembangkan lima elemen dalam dramatistic pentad untuk menganalisis bahasa individual seseorang dalam berekspresi. Lima elemen itu: pertama scene atau panggung tempat tindakan terjadi, kedua act atau tindakan yang terjadi, yang ketiga agent atau aktor yang 
melakukan, keempat agency atau alat yang digunakan aktor untuk mencapai tujuan, dan yang terakhir adalah purpose atau alasan mengapa orang melakukan hal tersebut. Dalam hal ini Facebook dapat disebut sebagai panggung dan selfie sebagai cara yang dilakukan untuk melakukan presentasi diri.

Fenomena selfie popular di berbagai media sosial saat user mengunggah foto selfie-nya dan tak jarang memilihnya sebagai foto profil melalui proses seleksi. Proses presentasi objek visual ini melalui tahap awal yang disebut pengelolaan kesan (impression management). "Individu melakukan seleksi dan mengontrol gambar yang akan dijadikan foto profil sesuai dengan perilaku yang diinginkan, tujuannya adalah untuk membentuk image yang diinginkan kepada orang lain." (Dayakisni, 2009).

Berdasarkan fenomena tersebut, maka rumusan masalah dalam penelitian ini adalah bagaimanakah manajeman kesan melalui foto selfie dalam media sosial Facebook?

\section{B. TINJAUAN PUSTAKA}

Teori yang mendasari penelitian ini yaitu Computer Mediated Communications dan keterkaitannya dengan presentasi diri, khususnya manajemen kesan. Selfie dalam penelitian ini merupakan salah satu media presentasi diri seseorang berbasis komputer. Selfie yang ditampilkan adalah foto yang sebelumnya telah melalui proses manajemen kesan. Dalam proses manajemen kesan membutuhkan syaratsyarat supaya kesan yang tercipta menjadi baik dan sesuai harapan. Goffman dalam Dayakisni (2009) menggambarkan manajemen kesan dijelaskan dengan teori dramaturgi. la berpandangan salah satu dasar interaksi sosial adalah komitmen saling timbal balik diantara individu yang terlibat dalam satu aturan yang harus dimainkan.

Oleh pakar lain, Kenetth Burke dalam Ruben (2013) dramaturgis sendiri memiliki lima elemen dramatistic pentad, antara lain: panggung atau scene tempat tindakan terjadi, tindakan atau act, actor atau agent, alat yang digunakan aktor untuk mencapai tujuan atau agency, dan alasan mengapa orang melakukan tindakan atau purpose.

Penelitian terdahulu yang berjudul Pieces of Me: Selfie Culture Trend yang ditulis oleh Dian Arymami mengatakan konsep selfie telah menjadi sebuah budaya yang menghasilkan ilusi diri. Gangguan yang diakibatkan selfie dapat menyangkut tentang seksualitas, objektifikasi, dan narsisisme. Hasil penelitiannya mengarah pada konklusi bahwa selfie sudah menjadi kebiasaan harian dan sebagai media dalam menggambarkan budaya kaum muda dan elit. Dalam Jurnal Internasionalyang berjudul Selfies and Visual Messaging as Visual Conversation: Reports from United States, United Kingdom, and China yang ditulis oleh James E Katz dan Elizabeth Thomas Krocker menyebutkan selfie memodali atau memediasi masyarakat dalam berkomunikasi secara visual. Dalam arti lain selfie bisa menjadi alternatif orang dalam menyampaikan maksud melalui ekspresi wajah seseorang. Dalam hasil penelitian tersebut juga mengungkap responden Amerika lebih banyak mengambil gambar selfie daripada Inggris dan Cina. Mereka mengatakan meskipun selfie hasil dari tindakan yang spontan, namun mereka akan menampilkan diri sebaik mungkin dengan berkali-kali mengambil selfie dan memperhatikan penampilan dan frame yang bagus. Poinnya adalah meskipun selfie merupakan hasil dari tindakan yang spontan, ternyata responden tetap menganggapnya sebagai sesuatu yang harus dipersiapkan. Hal tersebut sesuai dengan teori proses presentasi diri individu yang dilakukan dengan menyeleksi dan mengontrol perilaku yang diinginkannya.

\section{METODE PENELITIAN}

Penelitian ini merupakan penelitian kualitatif dengan pendekatan fenomenologi. Metode fenomenologi digunakan untuk memberikan kerangka cara memaknai 
suatu realitas. Peneliti melihat perspektif fenomenologi menunjukkan arti fenomena yang berkaitan dengan manusia. Jenis ini dianggap paling relevan sehingga metode observasi dan wawancara mendalam dilakukan untuk memberikan gambaran secara jelas tentang fenomena selfie dan cara seseorang mempresentasikan diri melalui foto selfie dalam Facebook.

Teknik sampling dalam penelitian ini adalah menggunakan purposive sampling yakni sampel diseleksi atas dasar kriteriakriteria khusus yang telah ditentukan oleh peneliti sesuai dengan tujuan penelitian. (Kriyantono, 2006:158). Dalam penelitian ini, peneliti memilih enam orang mahasiswa aktif Ilmu Komunikasi UMS angkatan 2009 hingga angkatan 2014 dengan masingmasing angkatan adalah satu orang. Alasan pengambilan informan dari jurusan tersebut karena peneliti mengetahui, berinteraksi langsung, dan memiliki akun Facebook beberapa mahasiswa Ilmu Komunikasi yang aktif mengunggah foto selfie. Selain itu subyek penelitian juga pernah mendalami ilmu tentang sosiologi komunikasi dan psikologi komunikasi.

Tak hanya itu, sesuai dengan pembagian periode perkembangan manusia Erick Erikson (Rakhmat, 2007:8), mahasiswa Ilmu Komunikasi telah memasuki tahap intimacy dan isolation. Suatu keadaan bahwa jika seseorang berperilaku positif terhadap diri dan sekitarnya, maka ia akan intim terhadap orang lain. Sedangkan sebaliknya, jika negatif, maka akan menarik diri dari lingkungannya atau isolasi. Selain itu mahasiswa juga tergolong pada usia yang sudah stabil dan dapat menentukan halhal yang akan diperbuat serta mengetahui dampak positif dan negatif atas perbuatan yang dilakukan.

Adapun untuk kriteria informan adalah pengguna aktif Facebook sejak lima tahun terakhir terhitung sejak Januari 2010 yang sebelumnya telah diobservasi melalui akun Facebooknya dan merupakan pengguna Facebook yang pernah melakukan pengunggahan foto selfie minimal sepuluh kali. Kriteria tersebut dipakai supaya peneliti mendapat gagasan yang mendalam dari informan tentang motif pengunggahan foto selfie dalam Facebook.

Sumber data primer dalam penelitian ini berasal dari wawancara mendalam dengan enam informan mahasiswa aktif Ilmu Komunikasi UMS sedangkan data sekunder berasal dari observasi. Penelitian ini diawali dengan observasi yang dilakukan pada bulan Mei 2015 dengan mengamati akun Facebook dari keempat narasumber. Kemudian dilaksanakan wawancara guna mengumpulkan informasi terkait dengan penelitian secara mendalam pada Bulan Oktober - November tahun 2015. Lokasi penelitian dilakukan di wilayah UMS, Pabelan, Kartasura, Sukoharjo.

Validitas data yang digunakan adalah triangulasi, yaitu teknik pemeriksaan keabsahan data dengan memanfaatkan sesuatu lain dari luar data untuk keperluan pengecekan dan pembanding data penelitian. Analisis triangulasi dilakukan dengan menganalisis jawaban informan dengan data empiris yang telah tersedia sebelumnya, misalnya teori dan hasil penelitian sebelumnya. Dwidjowinoto dalam Rakhmat Kriyantono (2006) mengungkapkan ada lima triangulasi, yaitu triangulasi sumber, triangulasi waktu, triangulasi teori, triangulasi periset, dan triangulasi metode. Dalam penelitian ini peneliti menggunakan triangulasi sumber dan triangulasi metode.

\section{HASIL DAN PEMBAHASAN}

\section{Manajemen Kesan dan Dramaturgi}

Goffman dalam Dayakisni (2009) menggambarkan manajemen kesan dijelaskan dengan teori dramaturgi, bahwa individu dalam menggunakan media bertindak sebagai pelaku pertunjukan teater. Goffman berpandangan salah satu dasar interaksi sosial adalah komitmen saling timbal balik diantara individu yang terlibat dalam satu role yang harus dimainkan.

Syarat-syarat yang perlu dipenuhi agar kesan yang diciptakan baik adalah sebagai 
berikut :

1. Penampilan muka (proper front)

Diekspresikan secara khusus agar orang lain mengetahui dengan jelas si pelaku. Proper front merupakan penampilan yang bersifat individual yang menentukan presentasi diri dan muncul sebelum audiens. Hal ini mencakup semua atribut ekspresif yang dibutuhkan untuk menjalani perannya. Informan E misalnya, atribut ekspresi yang ia gunakan adalah dengan senyuman manis, karena ia berfikir tentang konsep diri yang friendly dan ceria adalah dengan murah senyum.

\section{Keterlibatan dalam peran}

Individu sebagai aktor tentunya memiliki peran yang dijalankan. Semua informan adalah mahasiswa aktif di Universitas Muhammadiyah Surakarta (UMS) yang notabene perguruan tinggi Islam. Mereka memahami role sebagai mahasiswa UMS, salah satunya dengan menutup aurat maka, mereka akan senantiasa mengenakan pakaian yang menutup aurat pada saat berfoto selfie. Atau mereka yang berperan sebagai remaja akan bertindak sesuai dengan remaja pada umumnya. Atau yang aktif di salah satu organisasi kampus, maka ia akan sering mengunggah foto kegiatannya saat mengelola organisasi maupun berfoto dengan tokoh aktifis.

3. Mewujudkan idealisasi harapan orang lain tentang perannya

Informan sebagai mahasiswa, dirinya harus bertindak seperti mahasiswa pada umumnya. Terlebih lagi UMS sebagai salah satu universitas berbasis Islam tentu saja dalam berbusana, mahasiswa dan mahasiswinya harus menutup aurat. Informan yang didominasi perempuan mengatakan mengenakan pakaian syar'i adalah hal yang tak bisa ditawar. Informan C misalnya, ia menyinkronkan yang menjadi kesehariannya di dalam kehidupan kampus dengan foto selfie yang diunggahnya. la beralasan selain memang sudah menjadi pilihannya, hijab membuatnya terlihat lebih feminim dan cantik.
4. Mystification

Pada umumnya peran menuntut pemeliharaan jarak sosial tertentu antara aktor dan orang lain. Maksudnya, kedekatan emosional seseorang dengan orang lain belum tentu membuat keduanya dekat secara online. Hal tersebut memicu adanya jarak dan batasan komunikasi di dunia maya. Informan D menjelaskan pengalamannya tentang teguran yang ia dapat dari dosen. Secara emosional dosen tersebut dekat dengan dirinya dan juga berteman dalam Facebook, namun hal tersebut tak lantas membuat informan merasa nyaman dalam mengunggah segala sesuatu di Facebook. Hal itu membuat informan D memelihara jarak sosial pada lingkungan online atau dunia mayanya dengan orang lain.

\section{Pentad dalam Facebook}

Oleh pakar Kenetth Burke dalam Ruben (2013) mengungkapkan dramaturgi memiliki lima elemen dramatistic pentad, antara lain :

\section{Panggung atau scene}

Tempat tindakan terjadi. Ibarat akan mementaskan sebuah drama, aktor memerlukan panggung sebagai tempat untuk melangsungkan pertunjukan. Panggung dalam kajian ini adalah Facebook untuk menampilkan segala tindakan atau aksi yang dilakukan informan. Facebook dijadikan para informan sebagai panggung untuk melakukan perannya sesuai dengan tujuan awal mereka ber-selfie. Kesimpulan dari tujuan informan mengunggah foto selfie adalah untuk menampilkan diri semenarik mungkin agar mendapat kesan yang positif dari orang lain. Karena menurut informan, kesan yang baik akan membuat komunikasi terjalin secara efektif.

\section{Tindakan atau act}

Tindakan adalah sesuatu yang dilakukan dengan tujuan tertentu. Dalam hal ini tindakan yang dimaksud adalah selfie itu sendiri yang diunggah informan dalam jejaring sosial Facebook. Sebagai contoh informan B yang ingin mengkomunikasikan 
kepada orang lain bahwa dirinya adalah anak gaul, maka ia akan mengunggah foto-foto selfie bersama teman-teman nongkrongnya di cafe.

\section{Actor atau agent}

Dalam memainkan perannya dalam Facebook, informan sadar akan tindakan yang dilakukan. Mereka juga sadar bahwa mereka yang menentukan tindakan yang dilakukan sesuai dengan yang diinginkan. Informan A misalnya yang merupakan seorang aktifis dengan hobi berpetualang di alam bebas akan menampilkan diri melalui selfie dengan gaya layaknya aktifis pada umumnya, yakni dengan sering mengunggah foto di alam bebas atau foto kegiatan organisasinya. Informan D yang ingin menampilkan perannya sebagai perempuan yang anggun dan alim, maka dia akan menghindari gaya-gaya yang kekanak-kanakkan.

4. Alat yang digunakan aktor untuk mencapai tujuan atau agency

Alat utama yang digunakan dalam ber-selfie tentu saja adalah kamera. Ada bermacam kamera yang digunakan antara lain: kamera digital, kamera handphone, kamera kedap air, dan kamera go-pro. Dengan menggunakan tongkat narsis (tongsis), informan merasa sangat terbantu karena mereka dapat membuat objek lebih banyak dan sesuai dengan harapan dari yang ditangkap dengan kamera. Informan A yang lebih menyukai foto selfie outdoor mengungkapkan dengan bantuan tongsis background atau latar belakang terlihat lebih jelas dan menambah efek dramatis.

5. Alasan orang melakukan tindakan atau purpose

Bab sebelumnya telah disinggung mengenai studi fenomenologi yang menganggap manusia secara aktif dan sadar menilai pengalaman sehingga dapat memahami lingkungannya melalui pengalaman personal. Prinsip dasar fenomenologi menurut Stanley Deetz dalam Morissan (2013) yakni kesadaran. Manusia secara sadar memiliki tujuan atau alasan tertentu dalam melakukan tindakan. Sesuai wawancara yang telah dilakukan, semua informan mengaku secara sadar dalam melakukan selfie memiliki tujuan tertentu. Tujuan mereka dalam melakukan selfie bermacam-macam, mulai dari memperlihatkan eksistensi diri, ekspresi, menambah teman dan link jaringan sosial, memperoleh perhatian dan sanjungan, pamer, serta menyimpan file foto dalam jejaring sosial.

\section{E. PENUTUP}

\section{Kesimpulan}

Meskipun selfie dianggap sebagai tindakan yang spontan, namun para informan menyebutkan perlu menampilkan diri sebaik mungkin. Hal tersebut selaras dengan teori manajemen kesan khususnya dramaturgi bahwa Facebook sebagai panggung dan selfie sebagai act atau tindakan. Dalam bertindak, informan memperhatikan beberapa hal yang menjadi syarat agar kesan yang diciptakan baik. Informan mempresentasikan dirinya dengan memperhatikan penampilan muka, keterlibatan perannya, perwujudan idealisasi orang lain terhadap dirinya, dan mystification.

Selain itu, hasil penelitian mendukung bahasan Kenneth Burke tentang dramatistic pentad dengan masing-masing informan konsen kepada panggung, tindakan, aktor atau dirinya sendiri, alat-alat yang digunakan, dan alasan mereka melakukan tindakan tersebut. Terlebih lagi, selfie dalam hal ini merupakan jenis CMC yang memiliki ciri khusus dalam pola komunikasinya, yakni bersifat interaktif, editable, de massified, dan asinkron.

\section{Saran}

a. Bagi subjek

- Diharapkan mampu menggunakan teknologi dengan sebaik-baiknya dan bijak.

- Sebagai insan komunikasi diharapkan dapat mempraktikkan 
ilmu yang didapat dalam kehidupan sehari-hari supaya tercipta komunikasi yang efektif.

- Bagi penelitian selanjutnya diharapkan dapat menambah tinjauan pustaka mengenai fenomena selfie dan dapat melakukan penelitian dengan pandangan atau angle lain supaya memperkaya penelitian tentang fenomena media baru.

\section{DAFTAR PUSTAKA}

\section{Buku:}

Dayakisni, Tri \& Hudaniah. 2009. Psikologi Sosial. Malang: UMM Press

Julianita, Winda. 2010. Be A Smart \& Good Facebookers. Jakarta: PT Elex Media Komputindo

Kriyantono, Rachmat. 2006. Teknik Praktis Riset Komunikasi: Disertai Contoh Praktis Riset Media, Public Relations, Advertising, Komunikasi Organisasi, Komunikasi Pemasaran. Jakarta: Kencana

Morissan. 2013. Teori Komunikasi. Bogor: Ghalia Indonesia

Morissan. 2013. Teori Komunikasi Individu Hingga Massa. Jakarta: Kencana Prenada Media Group

Mulyana, Deddy dan Solatun. 2008. Metode Penelitian Komunikasi. Bandung: PT Remaja Rosdakarya

Rakhmat, Jalaludin. 2001. Psikologi Komunikasi. Bandung: PT Remaja Rosdakarya

Ruben, Brent D, dan Lea P. Stewart. 2013. Komunikasi dan Perilaku Manusia. Jakarta: Rajawali Pers

Sugiyono. 2007. Metode Penelitian Kuantitatif Kualitatif dan R\&D. Bandung: Alfabeta

\section{Jurnal:}

Arymami, Dian. Pieces of Me: Selfie Culture Trends. The First International Conference on Innovative Communication and Sustainable Development in Asean

Katz, James E and Elizabeth Thomas Crocker. 2015. Selfie and Photo Messaging as a Visual Conversation Reports from United States, United Kingdom, and China. International Journal of Communications 9 